Article

\title{
The Challenges for Implementing the Nagoya Protocol in a Multi-Level Governance Context: Lessons from the Belgian Case
}

\section{Brendan Coolsaet *, Tom Dedeurwaerdere and John Pitseys}

Centre for Philosophy of Law, Université catholique de Louvain, Collège Thomas More, Place

Montesquieu 2, B-1348 Louvain-la-Neuve, Belgium; E-Mails: tom.dedeurwaerdere@uclouvain.be (T.D.); john.pitseys@uclouvain.be (J.P.)

* Author to whom correspondence should be addressed: E-Mail: brendan.coolsaet@uclouvain.be; Tel.: +32-1047-4118; Fax: +32-1047-2403.

Received: 15 June 2013; in revised form: 30 September 2013 / Accepted: 8 October 2013 /

Published: 23 October 2013

\begin{abstract}
The Nagoya Protocol on Access and Benefit-sharing is the latest protocol to the Convention on Biological Diversity (CBD). Its implementation can lead to two fundamentally different processes: a market-oriented self-regulatory approach, which emphasizes the self-regulating capacity of the economic actors involved, or a normative institutionalist approach, which focuses on the norms and formal rules of institutions that not only support and frame, but also shape and constrain the actions of the players acting within them. This paper analyzes the challenges related to the implementation of the Nagoya Protocol in the specific case of Belgium, and evaluates the possibility of moving from a self-regulatory to an institutional approach of implementation, which we argue is necessary to achieve the objectives of the Protocol. This move is analyzed in the specific multi-level governance context characterizing the Nagoya Protocol, which has a natural tendency towards a market-oriented self-regulatory approach.
\end{abstract}

Keywords: self-regulation; institutionalism; European environmental policy; biodiversity governance; access and benefit-sharing (ABS); Nagoya Protocol; implementation challenges

\section{Introduction}

The Nagoya Protocol on Access and Benefit-sharing, or ABS, is the latest protocol to the Convention on Biological Diversity (CBD). Its origin goes back to the early days of the Convention as 
its core objective is to further the implementation of the third objective of the CBD, namely the fair and equitable sharing of benefits arising from the utilization of genetic resources. The Nagoya Protocol (hereafter "the Protocol") provides an agreement on a series of more detailed procedures and clarifies the rights and duties of the Parties, with the view of implementing the obligations embedded in Articles 15 and 8(j) [1] of the Convention, and its three core objectives pertaining to conservation, sustainable use, and benefit-sharing. These obligations include the respect by users of genetic resources and associated traditional knowledge of the domestic access and benefit-sharing (ABS) legislation of countries providing such resources, requesting formal prior informed consent from these countries upon access unless otherwise specified, and the sharing of benefits generated by the utilization of these resources. In return, provider countries agree to facilitate access to their genetic resources by offering legal certainty and clear and transparent procedures to request access.

Since the adoption of the CBD at the 1992 Earth Summit in Rio, ABS has become a major issue in international relations, as it has been seen by some as a way to redress the longstanding imbalances of the terms of North-South trade [2,3]. The inclusion of the concept of "fair and equitable benefit-sharing" as the third objective of the CBD can be seen as the developing countries' responses to increasing trends of privatization of benefits, arising from genetic resources and the socialization of the costs related to their conservation and protection [4]. Moreover, the concurrent negotiations of the General Agreement on Tariffs and Trade (GATT) Uruguay Round, which pushed for the strengthening of intellectual property rights, led developing countries to replace their common-heritage strategy by (re)claiming sovereign rights over their genetic resources [5]. While dealt with under the auspices of an environmental treaty, the adoption of the Protocol is thus not just about the environment but also about international equity as a crucial component of any environmental regime, as explicitly recognized since the Stockholm declaration of 1972 [6,7]. Never, since the negotiations of the Kyoto Protocol, has the subject of equity figured so prominently on the agenda of the international politics of the environment as during the tenth Conference of the Parties to the CBD, which led to the agreement of the Nagoya Protocol [8].

The importance of the issue is also reflected by the political priority given to the entry into force of the Nagoya Protocol. At the time of writing, provider countries are increasingly ratifying (or acceding to) the Protocol, while user countries, in particular the European Union and its Member States, have started preparations for timely ratification. However, the implementation of the Nagoya Protocol, as a typical "multi-level governance" case, is easier said than done. The very wide scope of subjects it addresses, and the multiplication of competent authorities and stakeholders handling these subjects at regional, national, and supranational level make the implementation, and the achievement, of the underlying objectives of the CBD through it, especially challenging. As such, for an efficient governance system to be developed, a continuous interaction between different policy levels, different departments within these levels, and different governmental and non-governmental actors will be necessary.

The implementation of the Protocol in a multi-level framework can however lead to two fundamentally different governance processes. The first is based on a market-oriented self-regulatory approach to the implementation of access and benefit-sharing [9,10]. Building on the seminal work of Ronald Coase, the self-regulatory approach to ABS assumes that emphasizing the self-regulating capacity of the concerned economic - private or public — actors (both for profit and not for profit) is the most effective and efficient mechanism to organize access to genetic resources and the fair and 
equitable sharing of benefits. The option in favor of market-oriented self-regulation does not mean that this mechanism cannot be subject to institutionalization and/or state support, but these means of support do not go beyond leveling the playing field between the actors involved in the bilateral player-to-player contracting. Therefore it is assumed here-in the line with approaches of bilateral contracting in rational choice institutionalism (for a global insight see [11,12]) or neo-classical economics - that the actors have fixed preferences and behave according to their expectations of how other actors will act.

The second type of implementation process is based on a normative institutionalist approach of public action, which focuses on the norms and formal rules of institutions that not only support and frame the spontaneous interaction between agents with fixed preferences, but also shape and constrain the actions of the players and their preferences [13]. This approach is not only normative because these formal or informal systems of rules propose a description of the permissible actions of people under a set of rules, but also because they propose a set of prescriptive norms giving the actors a reason for action. The institutionalist approach assumes that it is both possible and desirable that the social and political institutions give the actors a reason to comply with, or be governed by, collective rules [14].

In the context of the implementation of the Nagoya Protocol, the market-oriented self-regulatory approach will take the shape of market or quasi market driven implementation method, that is through the effective and efficient governance of decentralized voluntary agreements $[15,16]$. In this context, multi-level governance of ABS is mainly concerned with improving the coordination needed for establishing player-to-player contractual agreements between stakeholders in both user and provider countries, such as information sharing and harmonization procedures [17,18].

The normative institutionalist approach, on the other hand, will rely on the positive institutionalization of the core principles of the ABS regime within national legislation and public policies, beyond the minimal measures for the coordination of the bilateral contracting between economic actors [19]. While market-oriented self-regulation is, of course, likely to pursue general objectives of international equity (such as global justice or the protection of the rights of Indigenous and Local Communities) and ecological sustainability (such as conservation and sustainable use of biodiversity), the normative institutional approach translates these core normative principles of the Nagoya Protocol directly into positive public norms. In doing so, this second approach, unlike the first one, thus allows the competent authorities to guarantee that the regulation of access, and benefit-sharing serves the environmental and social objectives of the Nagoya Protocol and the CBD. This implementation can include legislative action, but can also proceed through public policies. It is also likely to take the form of so-called reflexive governance or meta-regulation, steering the process of implementation and supporting collective action that contributes to the goals of the Nagoya Protocol, in addition to "regulating social and individual action directly" [20,21].

This paper analyzes the challenges related to the multi-level governance nature of the Nagoya Protocol in the specific case of Belgium, which is especially relevant in this regard. With 340 companies, the number of biotechnology companies per capita in the country is among the highest in the world [22]. The majority of them are active in the health-care sector, making the country the third largest importer and exporter of medicinal and pharmaceutical products and medicines [23]. According to its own figures, the biopharmaceutical sector employs over 30,000 people, while providing $40 \%$ of the total private R\&D in the country [24]. The implementation of the Nagoya Protocol thus raises serious economic and political stakes for the country and this is clearly visible in Belgium because of 
its genetic resource collections, its industrial actors, and so on. However, more fundamentally, Belgium offers a particularly interesting political substrate for the analysis of multi-level governance processes. While the country is preparing the ratification of the Protocol (see Section 3 of this paper), it is party to a number of other international instruments and an EU Member State, both factors which will directly influence its implementation of the Protocol. It is also a highly decentralized federal state, comprising three Regions and three Communities, which share ABS-competences with the federal government. The multilateral and bilateral international obligations of the country notwithstanding, the competences that are relevant for the Nagoya Protocol are divided between the regional, federal, and European level-as well as the corresponding public administrations and agencies. Belgium, thus, presents a unique case, combining high economic stakes in the implementation of the Nagoya Protocol and a high level of decentralization, suitable for analyzing the multi-level implementation of an international agreement.

The questions underlying this paper are therefore the following: what are the consequences of the multi-level governance character of the Nagoya Protocol for its implementation in Belgium? How does the multi-level character of the implementation impact the choice between a self-regulatory approach and a normative institutionalist one? In addition, to what extent does the multi-level character restrain the political opportunity to move beyond a mere self-regulatory approach to implementation?

While some reflections on the state of the implementation are given in Section 3, this paper does not intend to provide the reader with a comprehensive study of the implementation of the Nagoya Protocol in Belgium: it is premature at this stage, and would exceed the scope of the paper. Nor does it aim to propose a prospective implementation handbook of the Nagoya Protocol for Belgium, as interesting that could be for the future. The paper, rather, uses the case of the implementation of the Nagoya Protocol in Belgium to depict how the multi-level character of the implementation favors some governance patterns over others, and how these features impose specific challenges for the (even modest) implementation of a normative institutional approach that would differ from the institutional status quo and facilitate the achievement of the objectives of the Nagoya Protocol.

In order to answer the above questions, the following section of our paper outlines our theoretical framework of self-regulation versus institutionalization, based on existing concepts in the literature. The theoretical approaches are adapted to the context of access and benefit-sharing of genetic resources, and their advantages and disadvantages with regard to the objectives of the Protocol are clarified. We then provide an in depth analysis of the consequences of the multi-level governance context for the implementation of the Protocol in Belgium. Third, we assess the constraints that such a multi-level implementation imposes on the possibilities for sustainable institutionalization of the core objectives. Our argument will be that the multi-level reality of the implementation of the Protocol explains, in part, the tendency towards a minimalistic market-based self-regulatory approach. As highlighted throughout this article, this market-based approach offers little guarantee as to the achievement of the core objectives of the CBD. For instance, private contracts do not necessarily take into account social and environmental goals, unequal bargaining power between trans-national actors threatens the fairness of contracts and current intellectual property rights appear at odds with the facilitation of access to genetic resources. The final section concludes. 


\section{The Institutionalization Process of Access and Benefit-Sharing Sharing Objectives}

The implementation of the Nagoya Protocol is an ideal case to study the tension between the minimum market-oriented self-regulatory approach and the institutionalization of ABS introduced earlier, as illustrated by the discussion on the proposal for an EU Regulation on ABS between the European Commission and the European Parliament. The European Commission's text proposed minimal regulation of the Nagoya Protocol [25], relying mainly on a self-monitoring system (i.e., due diligence) for the utilization of genetic resources. This approach was first denounced by the Committee on Development of the European Parliament, stating that "[...] when elaborating its proposed system for the implementation of the Nagoya Protocol, the Commission has obviously been more mindful of users' than of providers' interests and concerns. Minimizing users' burdens and costs and facilitating easy access seem to be top priorities, while the same can definitely not be said about promoting effective benefit-sharing (BS)" [26]. The European Parliament Committee on the Environment, Public Health and Food Safety's response, while preserving the idea of a self-monitoring system proposed by the Commission, extends the rationale behind the draft proposal by "guaranteeing [...] ethical conduct", "[reinforcing] international equity", and putting fair and equitable benefit-sharing as well as conservation and sustainable use of biodiversity back on center stage through the amendment of the EU proposal [27].

This tension is also mirrored in the different conceptions of public governance, which are at play in the implementation process of the Nagoya Protocol, and especially the two approaches - self-regulation and institutionalization - defined in the introduction.

It should be noted that these approaches are ideal-type analytical distinctions, rather than realist descriptions of the complete set of possible nuances found in between them. The difference between these approaches is not intrinsically linked to the role they might give to formal institutions, civil society representation or market mechanisms in the governance toolbox. The market-oriented self-regulatory approach, for instance, might have recourse to formal institutions to govern the transactions costs of the social interactions - and more widely, uncover what "right/accurate rational behavior" should be. The analytical distinction between both approaches resides in their conception of collective action. The self-regulatory approach assumes that the governance has to accompany an already set range of preferences and coordination behaviors: the role of the state is then to let human action and coordination take its natural inclination. The normative institutionalist approaches assumes there is no such (politically relevant) pre-set behavioral range and that the formation of collective action is, and must be, framed by collective institutions.

In this context, the analytical distinction between these registers goes along with a normative distinction. The self-regulatory approach assumes that the question of the collective justification of the outcome can be handled at the level of the self-regulated coordination, based on proven efficacy and efficiency of outcomes resulting from a decentralized iterative learning process. In contrast, the normative institutionalist approaches posits that the justification derives from a reasoned legitimation process at the level of the institutions involved (which might also include criteria of efficacy and efficiency, amongst others, but from the point of view of criteria of institutionalized justification processes). 
Finally, this analytical and normative distinction also opens two pragmatic distinctions. Even if the market-oriented self-regulatory approach does not preclude state support, state support will tend to be used mainly in normative institutionalist frameworks. Likewise, even if a normative institutionalist framework does not preclude using market or quasi-market driven policies, these mechanisms will tend to be set within state organized institutions. The self-regulatory and institutionalist approaches are thus analytically distinct as to their conception of collective action and will tend-despite probable overlapping and a wide range of intermediate governance patterns - to diverging political options.

Taking into account these distinctions as well as their nuances, the first of these political options in the context of the implementation of the Nagoya Protocol, based on self-regulation, leads to a (quasi) market-centered economic rationality [20]. In order to achieve the objectives of the Nagoya Protocol, the aim of this form of regulation is to create a level playing field, which is both legal and international, to facilitate access to genetic resources, thereby fostering the creation of global exchanges based on private contracts between users and providers of genetic resources. In this regard, the main goal of the coordination between the different actors is to contribute to the standardization of the procedures that can govern the market for genetic resources, while taking into account some specific needs of particular sectors such as the research sector, the agricultural sector or the exchange of pathogens in the context of pandemic prevention and cure. Such a market-based perspective fits well with a minimalist definition of meta-regulation by public authorities, as analyzed in the literature on the shift from direct state regulation to self-regulation by private actors: "Rather than regulating prescriptively, meta-regulation seeks to stimulate modes of self-organization within [a private firm] in such a way as to encourage internal self-critical reflection about its performance" ([28], p. 13). The institutional environment, however, is never absent from the self-regulatory approach: self-regulatory approach does not rule out legislative rules or state control per se, as it also requires a legal contractual framework, private international law regulations, and/or judicial control of public action. Nonetheless, the role of collective institutions only entails providing information and enforcement mechanisms that reduce actors' uncertainty [19].

The implementation process of the Nagoya Protocol can also be framed within a normative institutionalist perspective of political rationality [19]. Notions of social justice and ecological sustainability are not only ethical principles to be achieved by self-regulated actors within a set of procedural constraints. In an institutional perspective, these normative goals are translated both into positive substantial and procedural legal principles, and in public policy supporting collective action that contributes to these normative goals. It includes prescriptive provisions and positive public action aiming to explicitly up-scale environmental and social standards, thereby overcoming some of the drawbacks of a self-regulated approach to implementation described earlier [29].

The normative institutionalist approach to implementation goes beyond the classical "command and control" conception of the legal order. Following the insights from the work in sociological institutionalism (for an application to the field of ABS, see [10]; for seminal sources, see [30-33]), this approach might also come to understand public policy as a reflexive process between the normative perspectives emanating from the social sphere (including the scientific, economic, and cultural sub-systems) and the rules of recognition defining the legal sphere. In this framework, the normative institutionalist approach to implementation could contain elements of meta-regulation of self-regulated 
actors, but such meta-regulation also goes beyond the minimalistic approach of coordinating a set of actors based on the expression of their preferences in market-based and research transactions.

Building on theories of network governance, Sørensen and Torfing summarize different forms of meta-regulation that go beyond the minimalistic meta-regulation of self-regulated actors and aim at organizing processes of social learning and norms based justification that go beyond decentralized learning [34]. The first form of meta-regulation is the interference of a meta-regulator. While self-regulated networks rely on the spontaneous or oriented convergence of actor's preferences, it appears nonetheless that such a convergence is not guaranteed. In the context of ABS, relying mainly upon contracts agreed between private users and providers of genetic resources might generate numerous disagreements for the negotiation of issues such as the access conditions, the benefit-sharing requirements, the temporal and material scope of agreements, etc. The persistence of these disagreements undermines the effectiveness of the network of actors that are part of the ABS regime and their ability to settle agreements. In such cases, interference by a meta-regulator (this could be the state or an actor appointed by the state) might be judicious, whether through direct process management or as a fully-fledged participant in the negotiation [34]. An obvious candidate for such meta-regulation is state support for the drafting of standard agreements for researchers, managers and users of collections of genetic resources, such as an update of the Micro-Organisms Sustainable use and Access regulation International Code of Conduct (MOSAICC) code of conduct discussed below.

While regulated networks can be in need of conflict mediation to remediate ineffectiveness, they might also require some form of public management process to be governable [34], thereby specifying the "rules of the game" in which actors interact and negotiate [35], which is the second form of meta-regulation. Sørensen and Torfing identify three options for the provision of ground rules that can modify the rules of the game: (1) the use of incentives; (2) the redistribution of resources between actors; and (3) the threat of re-centralization of regulation (the "shadow of hierarchy") [34]. These three options find a political translation in the implementation of the Nagoya Protocol. For the first option, an illustration of game structuring through the use of behavioral incentives (which are not necessarily monetary incentives) can be found in the possible creation of quality labels for so-called "national trusted collections". In line with the EU notion of EU trusted collections, these labels can be implemented through auditing procedures, such as those in place for ISO certification. The second option, the redistribution of resources among the stakeholders, allows the state to level the playing field, thereby strengthening weaker actors and, thus, fostering fairer agreements [21]. This latter goal might, for instance, be met through the possible role that international development cooperation could play in developing specific capacity building projects in developing countries and/or for indigenous and local communities. Finally, through "re-centralization" - the third option-Morgan's "shadow of competition", which characterizes market-based meta-regulation [20], is replaced by a "shadow of hierarchy", under which the meta-regulator explicitly leaves the door open for direct prescriptive intervention in case of ineffective self-regulation by the stakeholders. The regulator acts in that case both as a last resort legislator and as a negotiation warning for the parties [36].

The third form of meta-regulation relies upon identity formation, which consists in shaping common understanding of the actors on how they ought to handle and interact with other actors (i.e., the appropriateness of their actions), as well as developing collectively agreed objectives [34]. This integration approach is often presented as a way to enhance the political capacities, equalize the distribution of these 
capacities, and "increase the democratic quality of societal governance processes" ([34] p. 177). However, it first and foremost constitutes a collective consensus building method [37-40]. As such, the reciprocity of user and provider measures under the Nagoya Protocol is a perfect example of what will eventually need to become a common vision of ABS. Too often, benefit-sharing is viewed as a cost or a burden for users of genetic resources [41], whereas it could also serve as an incentive for providers to facilitate access and promote conservation activities, which eventually also benefit users. However, the development of a common narrative also contributes to building social legitimacy for the implementation process of the Protocol. The narrative designates a biographical dimension when it covers the succession of the facts, interactions, and steps of the decision-making process. It constitutes the whole set of meanings orienting the supposedly shared reading and interpretations of the Protocol $[42,43]$. Finally, it designates the process by which the actors are led to think they are an effective part of a collectively shared and deliberative process [44]. In the ABS context, this could mean that relevant stakeholders such as civil society members (e.g., environmental and human rights NGOs) are supported in following the day-to-day implementation of the Nagoya Protocol. This is especially relevant as, in the current state of affairs, few Belgian NGOs are involved in following up the implementation of the Nagoya Protocol and/or have the necessary resources at their disposal to do so [45].

These different types of prescriptive provisions and positive public action are examples of what could be done to institutionalize ABS, thereby guaranteeing that the objectives of the CBD — biodiversity conservation, sustainable use of its components, and fair and equitable benefit-sharing - are met through the implementation of the Nagoya Protocol. The interference by a meta-regulator, for example, enables the content of ABS-agreements to be influenced, for instance, by helping stakeholders to identify the circumstances under which benefit-sharing can be deemed fair and equitable or to make sure that benefits are used in accordance with the environmental objectives of the Convention. In the same vein, the use of incentive systems rewarding pro-active implementation strategies by key actors can play a role in up-scaling the level of positive involvement in the ABS regime. The strength of the motivation of stakeholders to comply is indeed likely to be a determinant factor for reaching the ABS objectives [46], especially with private stakeholders who currently prefer to trade with informal providers that do not follow benefit-sharing standards [47]. Another barrier to the fair and equitable benefit-sharing objectives of the Protocol is the unbalanced bargaining power resulting from asymmetries in information, knowledge, negotiation skills and capacity. However, this can be solved by institutionalizing a form of redistribution of resources between the stakeholders, as described above.

In contrast, in a self-regulatory framework, the sharing of benefits and the conservation and sustainable use of biodiversity are seen as possible extra-contractual consequences of the contract-based transactions between users and providers (i.e., one contractual arrangement might have better side-effects on the environment than another). The realization of both these environmental and social goals is thus limited to the effectiveness of the national procedures regulating and monitoring these extra-contractual obligations, within a space of political action framed by the market-based tools. Under such a framework, the implementation of the Nagoya Protocol only relies on best efforts of private actors and on the public promotion and management of a transparent global system of exchange of genetic resources. This simple facilitation of a market of genetic resources is thus doomed to fall short of achieving the objectives of the Protocol, as "commercial mechanisms leave very little room to 
incorporate broader, social goals, such as securing human needs and equity" and protecting the environment $[18,48-50]$.

\section{Belgium as a Multi-Faceted Case of Multilevel Governance}

Belgium ratified the Convention on Biological Diversity in 1996, which entered into force (for Belgium) in 1997. Following the ratification, a number of biodiversity-related initiatives were taken by the different power levels in light of the implementation of the CBD. Some of these initiatives, such as the 2006 National Biodiversity Strategy and the 2010 Federal Plan for the integration of biodiversity in key sectors, already included some ABS provisions. These provisions mainly supported capacity building and awareness-raising activities, both domestically and abroad and the establishment of standard procedures for the exchange of biological material, such as the "Micro-organisms Sustainable Use and Access Regulation International Code of Conduct" and the "Standard Material Transfer Agreement", discussed below. In 2005, following the European Directive 98/44/EC on biotechnological inventions, which refers to Articles 8(j) and 15 of the CBD [1], Belgium also introduced a disclosure requirement for biological material. The amended patent law now requires geographical origin of the biological material that has been used as a basis for new inventions to be included in patent applications [24,51].

Belgium signed the Nagoya Protocol on 20 September 2011, after having played an important role in its establishment: the country held the European presidency and occupied a seat in the Bureau of the Conference [52] during the negotiations in Nagoya. Belgium currently represents the EU in the Bureau of the Intergovernmental Committee for the Nagoya Protocol (ICNP) [52] and it aims to be a Party at the first Meeting of the Parties to the Protocol. The implementation and ratification of the Protocol are, therefore, of high political priority for the country.

However, no existing national legislation currently regulates access and benefit-sharing obligations as understood by the Protocol [51]. The implementation of these obligations will need to take place simultaneously on different power levels. The very wide scope of subjects it addresses, the multiplicity of social sub-systems and languages (scientific, economic, administrative) involved and the multiplication of competent authorities and stakeholders it stages, lead to what has been called the "erosion of traditional bases of political power" [53]. This phenomenon covers various dimensions, amongst which we will focus in particular on three key dimensions that have been underlined in the literature on multi-level governance: (1) the internationalization of the policy regime; (2) the denationalization of the state; and (3) the destatization of the political system [21,54-56]. This section analyzes how the implementation of the Protocol works in these three dimensions.

The internationalization of the ABS policy regime leads not only to a multiplication of international actors (UN bodies, regional bodies, such as the EU and nation states) but also to a "problem of interplay" between existing international norms regulating similar and/or related issues [57,58]. The Nagoya Protocol is both directly and indirectly influenced by issues such as biodiversity conservation, international trade, agriculture, intellectual property, and indigenous and local communities' rights, all of which are regulated through different international institutions and sets of norms.

The second process is the denationalization of the state. Although recent evolutions in international environmental law have confirmed national sovereignty over national resources such as genetic 
resources and marine territorial waters [59], the nature of the ABS-issues requires a decentralized approach in order to be effective. Power and competences are thus distributed on a territorial scale, allowing for national, sub-national, and local power levels to co-govern genetic resources and traditional knowledge. This process is particularly relevant in a federal state such as Belgium, where ABS-related competences are scattered around three different levels of competence (federal, regional and community). Moreover, the vertical division of powers between federal and federated entities is coupled with a horizontal division. The large range of issues covered by the Nagoya Protocol also implies an extended horizontal administrative distribution of ABS-related competences within each of the power levels.

But this decentralized approach is not only applicable to "official" authorities. Hence, the third shift operated by multi-level governance is a destatization process in which power is shared between governmental and non-governmental entities. The shift from "government" to "governance" is clearest in this third aspect of multi-level implementation. Implementation of ABS, with its multiple incidences on private economic, social, and environmental interests, implies active participation of civil society, research actors, ex situ collections and, in particular, private companies utilizing genetic resources.

\subsection{Internationalization and Institutional Interplay}

The existence of related international norms discussed in different fora has direct consequences for the implementation of the Nagoya Protocol through national country legislation. First, for those countries that ratified $\mathrm{CBD}$, such as Belgium [60], little choice is left with regards to the ratification/implementation of the Protocol. The Nagoya Protocol builds on existing ABS provisions included in the CBD, particularly in its Articles 8(j) and 15 [1]. The latter forms the core ABS provision of the Convention. Under Article 15 [1], Parties to the CBD recognize the sovereign rights of States over their natural resources (Article 15.1), endeavor to create conditions to facilitate access to genetic resources (Article 15.2) and commit to taking "legislative, administrative or policy measures" in order to share the benefits arising from research and development on genetic resources and traditional knowledge, in a fair and equitable way and based upon mutually agreed terms (Art.15.7). Article 8(j) [1] adds that Parties to the CBD shall "respect, preserve and maintain" traditional knowledge held by Indigenous and Local Communities (ILCs) and ensure application of this knowledge is done with approval and involvement of these Communities. Through its ratification, Parties to the CBD are committed to taking national measures with the aim of complying with these ABS provisions. Ratifying and implementing the Nagoya Protocol can thus be seen as a legally sound way of taking the implementation of these ABS provisions under the CBD forward, in a mutually agreed way with the other Parties to the CBD. Furthermore, and deriving from this, non-ratification of the Nagoya Protocol has obvious disadvantages. In a situation of non-ratification, international entry into force of the Protocol would still require clarifying the current Belgian legal framework in light of possible future relations of Belgium as a non-Party to the Protocol with Parties to the Nagoya Protocol. Failing to do this would generate legal uncertainty and inhibit transparency, both prominent aspects of the implementation of the Nagoya Protocol, thereby potentially increasing transaction and litigation costs for users and providers [51]. This clarification would transpose the legal obligations from the CBD in Belgian law, but nevertheless be different than setting-up full-blown measures required for the 
implementation of the Nagoya Protocol, creating a confusing situation for users and providers where the same issue is covered by several different legal regimes.

Alongside the CBD, another instrument also regulates international access and benefit-sharing: the 2001 International Treaty for Plant Genetic Resources for Food and Agriculture (ITPGRFA) [61]. The objective of the ITPGRFA is strikingly similar to the objective of the Nagoya Protocol and its stated proximity with the CBD [62]. Its scope, however, is much more limited, applying only to a pre-defined list of plant genetic resources for food and agriculture. While both instruments aim to establish an international access and benefit-sharing regime, their approach is different. The ITPGRFA is designed to establish a multi-lateral system based on standardized contracts, facilitating access to common-pooled resources and sharing benefits through an international benefit-sharing fund. The CBD and the Nagoya Protocol, as we have seen, are based on bilateral player-to-player exchange of resources, leaving exchange protocols as well as access and benefit-sharing conditions to the discretion of Parties and stakeholders' arrangements [63].

The issue of the protection of ILCs is covered by a series of international instruments in the area of development cooperation and sustainable development, to which Belgium is also a Party. In particular, the 1957 International Labor Organization (ILO) Convention No. 107 on Indigenous and Tribal Populations, the ILO Convention No. 169 on Indigenous and Tribal Peoples, and the United Nations Declaration on the Rights of Indigenous Peoples. The latter is also explicitly noted in the preamble of the Nagoya Protocol and might therefore provide a framework in the further elaboration of decisions under the Nagoya Protocol relevant to the rights of ILCs. Agenda 21, adopted at the 1992 United Nations Conference on Environment and Development (UNCED) in Rio, also applies in this context. Its Chapter 26 focuses on the role of indigenous people and their communities. It is provided that such communities possess a unique knowledge of their environment and the natural characteristics thereof. Consequently, indigenous people and their communities should acquire the right of self-determination, manage their own resources and participate in the decision-making on development programs affecting them. While these instruments are mainly of a non-binding nature, they do provide for additional international norms with regards to the protection of ILCs and their knowledge, which Belgium is bound to honor, independently from possible implementation of the Nagoya Protocol.

Discussions at the World Trade Organization (WTO) and the World Intellectual Property Organization (WIPO) also interfere with the implementation of the Nagoya Protocol [57,64]. Although the Nagoya Protocol is now the main instrument for the protection of genetic resources and traditional knowledge, misappropriation by patents granted in violation of the legislation of the providing country are to be covered by the WIPO and the WTO's Trade Related Aspects of Intellectual Property Rights (TRIPS). These overlaps have not only influenced the negotiations of the Convention in 1992, but also those of the Protocol in 2010, with pressure from WIPO to water down user obligations and the compliance mechanism related to property rights during the process [48]. The last meeting of the WIPO Intergovernmental Committee on Intellectual Property and Genetic Resources, Traditional Knowledge and Folklore (IGC) focused on the biodiversity-related disclosure requirements in patent applications [65,66], a debate which lasted for nearly 15 years and was finally dropped in the negotiations in Nagoya. This same point has also been discussed at the WTO since the beginning of the Doha Development Round (2001), through the amendment of Article 27.3 (b) of the TRIPS agreement [67]. The WTO discussion also includes a proposal to include a requirement for prior 
informed consent and proof of benefit-sharing into the TRIPS Agreement, in order to reconcile it with the CBD's ABS provisions. Opposition to the disclosure requirement through amendment of the TRIPS, led by the United States, has argued that prior informed consent and benefit-sharing can be achieved through a contract-based system, thus relying on the market and the self-organization of the stakeholders [68].

Finally, Belgium is a member of the EU and therefore the possible legal action in Belgium on regulation of ABS issues is likely to be constrained by decisions taken at the EU level. The European Commission's proposal for a regulation on ABS [25] aims to harmonize user-compliance measures among its member-states. It relies on the establishment of minimum features of due diligence measures, obliging user of genetic resources to transfer information along the development chain to guarantee that genetic resources and traditional knowledge were accessed in accordance with applicable legal requirements. The European Union, however, is not only an international organization but also a political layer in itself, with its own collective institutions, jurisprudence, and legal order. Hence, it will also contribute to a process of denationalization of its member states (see the next point).

This non-exhaustive overview of the consequences of internationalization of norms, in subject matters that impact on ABS, shows that some international treaty obligations or recognized general norms are mutually supportive of the ABS implementation process, while others contradict or might slow down the adoption of effective ABS regulation. Such interplay between regimes clearly has an implication for the implementation process of ABS in a country such as Belgium. In particular, instruments like the different ILO conventions, Agenda 21 or the ITPGRFA are mutually supportive of (or even reinforce) the social and environmental objectives of the Nagoya Protocol. Therefore, the parallel work on the further development and implementation of these related international agreements can clearly contribute to the institutional approach to the implementation of the Nagoya Protocol as further discussed below. Other processes, like the WTO, WIPO, and the current EU proposal seem to influence the implementation of the Nagoya Protocol through market arrangements and patent protections, thereby contributing to a self-regulatory approach.

\subsection{Denationalization}

The possible modes of regulation of access to genetic resources and sharing of benefits from their utilization are influenced by the distribution of environmental competences over regional entities in many federal states, on the one hand, and by the transfer of some environmental competences to transnational federal entities-, such as in the case of the EU—on the other hand. These dynamics play a prominent role in Belgium and permit analysis some of the key features that also play a role for many other countries dealing with ABS.

As in many federal states, the main environmental competences in Belgium are situated at the level of the sub-national federated entities. Prominent examples of such regional environmental regulation are the case of Wales in the UK or the German Länder. A number of environmental competences are reserved for the Federal State, some of which are key for ABS, such as the export, import, and transit of non-indigenous plant varieties and animal species or the exercise of environmental and nature conservation competences within the Belgian territorial sea. However, despite these reserved competences, the three Regions (Flemish Region, Walloon Region, and Brussels-Capital Region) have 
the greatest responsibility in biodiversity-related issues, including the protection of the environment and the conservation of nature.

To illustrate how this influences the implementation of the Nagoya Protocol, let us take for instance the case of the existing legislation on physical access to and use of genetic material. The legislation is dependent on the relevant authority, which means that each Region and the Federal level have their own rules. However, it also depends upon the type of ownership (private, public, or res nullius) and the existence of restrictions on the ownership, such as specific protection for protected species, protected areas, forests, or marine environments. As regulated, for instance, by the 1997 Flemish Government Nature Conservation Decree, all acts that are not understood to include the normal maintenance of vegetation require a permit, including for commonly accessible green areas such as parks and gardens [69]. In the Walloon Region, however, permit delivery is regulated by the regional Code for urban and land planning [70], which regulates acts in zones previously prescribed by the government as being in need of protection, such as Natura 2000 sites. In the Brussels-Capital Region, different rules apply for protected and non-protected areas: while the collection of natural resources requires no permit for unprotected parks, gardens, or squares, and any acts implying the adaptation of the vegetation in protected areas are strictly regulated by the 2009 Nature Conservation Ordinance [71]. Finally, access to marine resources is regulated by federal laws on the protection of the marine environment and the exclusive economic zone, containing specific rules for scientific research using resources over which Belgium holds sovereign rights. All four power levels have, thus, appointed specific authorities for the handling of physical access requests and provide for different administrative sanctions in case of non-compliance. Even though the Nagoya Protocol has not been ratified yet and ABS is not explicitly covered by these dispositions, it is clear that, in Belgium, both access and benefit-sharing will be implemented in a similar way to these dispositions and that the three regions and the Federal State will each have their own access rules under the Nagoya Protocol.

Although the implementation of the access provisions of the Protocol is likely to be conducted by environmental ministries and administrations, other (non-environmental) ABS-related competences are equally scattered around vertically and horizontally in Belgium. Agricultural policy, including the application of common European measures is also mainly a regional competence, with the exception of the standardization and monitoring of the quality of raw and vegetal material, which is a reserved federal competence. Regions are also the main responsible authorities with regards to economic and industrial policy, even if the Federal government retains full competence over competition law, trade practices and intellectual property, all which could play a role in the implementation of the Nagoya Protocol.

Research, another key aspect of the implementation of the Nagoya Protocol, is divided differently between different power levels. The Flemish and French Communities are first in line, as they regulate fundamental research and higher education. However, the regions and the Federal government are competent in the field of research related to the exercise of their competences, including for instance economically oriented and industrial research (Regions) or the organization of data exchange networks between scientific institutions on the national and international level (Federal government). Finally, foreign policy and development cooperation are divided between the different entities according to the principle "in foro interno, in foro externo" [51]. 
Even though Belgium will be a single Party to the Protocol (once ratified), it remains bound by political dynamics at sub-national level, which distribute ABS-related competences between and within the different power-levels.

\subsection{Destatization}

It is one of the most challenging features of the ABS framework that access and benefit-sharing is legally grounded in the national state's sovereign rights over genetic resources, while in practice "it is mostly private actors that manage transjurisdictional transactions of genetic resources" ([72], p. 48,56). The authority to grant access to genetic resources, for instance, is a prerogative of the State, but can be attributed by the State to well identified non-governmental entities such as research institutes and ex situ collections. In contrast, those acquiring and using genetic resources are in many cases non-state entities, mostly researchers and private companies. Furthermore, the terms of the exchange (i.e., Mutually Agreed Terms, MAT) between these actors are normally set out in private law contracts (such as Material Transfer Agreements), but must comply with the rules and procedures for MAT established in the provider countries' legislation upon accessing the resource [73] and the rules for monitoring the establishment of MAT in the user countries' legislation [73]. Therefore, in practice, power over ABS implementation is shared between governmental and non-governmental entities situated both in the user and provider countries. Implementation of ABS, with its multiple incidences on private economic, social, and environmental interests, implies active participation of civil society, research actors, ex situ collections and, in particular, private companies utilizing genetic resources.

The research community, private, or public, is arguably the stakeholder group most affected by ABS under the CBD and the Nagoya Protocol. This explains why the sharing of benefits for the exchange or the utilization of genetic resources is mostly self-regulated by the sector, with each institution proposing its own rules and standard agreements. Some stakeholders have taken a leading role in formulating standard contractual clauses and procedures for establishing private law agreements that can be used by the research community and which are compliant with the provisions of the Protocol.

In Belgium, the major providers of genetic resources, the Belgian Coordinated Collection of Micro-organisms (BCCM) and the National Botanic Garden, each have their own codes of conduct aiming to foster conformity of the distributed genetic resources with the PIC requirements of the provider countries. The BCCM launched the international Micro-organisms Sustainable Use and Access Regulation International Code of Conduct (MOSAICC) initiative in 1997: MOSAICC is a voluntary code of conduct to facilitate access to microbial genetic resources in line with the CBD, the TRIPS Agreement, and other applicable national and international law, to ensure that the transfer of material takes place under appropriate agreements with the downstream users and is monitored to secure benefit-sharing. It aims, in particular, to develop an integrated conveyance system that has reliable tools to evaluate the economic value of microbiological resources; that provides validated model documents with standard provisions to enable tracking via an uncomplicated procedure, widely applied by microbiologists; and that combines valuation and tracking in one system for trading of microbiological resources, with balanced benefit-sharing for those that are entitled to be rewarded for the services and products they provide to society, and with the countries of origin of the genetic resources. The BCCM uses a standard Material Transfer Agreement (MTA) for getting access to the 
genetic resources of its public collection, which is established according to the guidelines of the MOSAICC code of conduct. The MTA stipulates that anyone seeking to access genetic resources held by the BCCM has the responsibility to obtain any intellectual property licenses necessary for its use and agrees, in advance of such use, to negotiate in good faith with the intellectual property rights owner(s) to establish the terms of a commercial license; taking also into account specific national laws regarding Article 15.7 of the Convention on Biological Diversity [74] as to conditions concerning benefit sharing (Art.8 of the BCCM MTA) [67].

The National Botanic Garden of Belgium has joined the International Plant Exchange Network (IPEN), a network of botanic gardens that organizes the exchange of living plant specimens. IPEN members have adopted a code of conduct regarding access to genetic resources and benefit-sharing. In line with the code, the Botanic Garden only accepts plant material that has been acquired in accordance with the provisions of the CBD. The Garden supplies seed material to other IPEN members, under the same terms under which it was acquired and unless an "agreement on the supply of living plant material for non-commercial purposes leaving the International Plant Exchange Network" [75] is signed by authorized staff.

As shown elsewhere [51], more standardized benefit-sharing procedures tend to provide better guarantees to meet the social and environmental objectives of the Protocol, while at the same time offering better economic perspectives by increasing legal certainty and transparency for all the actors. The necessity of accommodating sectorial differences in such standardized procedures will, however, require some form of flexibility in the exchange protocols of genetic resources. The latter can easily be achieved while taking into account a set of standard provisions and/or guidelines aiming to safeguard the objectives of the Protocol and the Convention, in particular those in the interests of broader society, such as fair and equitable benefit-sharing and the conservation of biodiversity.

\section{Assessing the Opportunities for Institutionalization in a Multi-Level Governance Framework}

Each of the three dimensions of the multi-level governance aspect has a consequence on the possibility of moving from pure coordination of the actors involved in transactions with genetic resources towards a full-fledged institutionalization of the social and environmental objectives of the Protocol. As described earlier, this institutional approach can take place under different forms: as national legislation or national public policy under the form of interference by a meta-regulator, public management, or identity formation.

The first impact of multi-level governance on the choice between the two types of implementation is related to the internationalization aspect analyzed above. As an EU member state, Belgium could benefit from an environmental watchdog with a strong environmental record and through which environmental policy making can be considered in a longer term than if handled individually by each member state [76]. The EU, through its "acquis communautaire", could furthermore help to upscale environmental concern by creating a common understanding between its member states of the social and environmental importance of access and benefit-sharing. In addition, more generally, the internationalization and the regime interplay is far from being incompatible with an institutionalist implementation approach. For those issues that remain to be clarified in discussion between various regimes before a possible transposition in the national legal frameworks, public policy could already 
contribute in a first stage to the implementation of the objectives of these agreements. This applies in particular to the case of strong and pre-existing international institutions and norms set by instruments such as the ILO Conventions, Agenda 21, the ITPGRFA, and the CBD itself. As the implementation of the Protocol is only in its first steps, it is quite likely that the Nagoya Protocol could benefit from a form of shared institutional identity brought by other international environmental and social instruments.

However, Belgium's geopolitical situation might lead the country toward market-centered institutional arrangements. As a small and extremely open economy, the country is highly dependent upon international trade, which makes it a suitable candidate for the influence of "the shadow of competition" [20]. Furthermore, the current economic financial crisis in the Eurozone, combined with the economic weight of the biotechnology sector in the EU, could also reframe general discussions in the EU around an economic rationality, be it at the level of their content, or at the level of their governance pattern. The European Commission's proposal for a regulation on ABS [25] appears at odds with the core environmental objectives of the $\mathrm{CBD}$, containing little if no provision for conservation and sustainable use. As Kamau et al. maintain, the Commission rather views the Protocol as "an undesired obstacle to free R\&D" ([77], p. 261) and its power to legislate could then rest on the EU competence for external trade. However, this would require public acknowledgment that the Protocol is an instrument for trade, which would equally run counter its own objectives. Additional challenges might arise from the interplay between different international regimes dealing with genetic resources trade. As neither WIPO nor the WTO include the protection of providers of genetic resources and intellectual property rights in their legal devices, the on-going conflicts over intellectual property rights within the international ABS regime are likely to persist. By polarizing the positions, these discussions further delay the establishment of effective monitoring systems for the utilization of genetic resources, with disclosure requirements seen by some as an essential mechanism to fight biopiracy [78]. It is likely that countries will want to wait until more clarity concerning disclosure requirements is provided at WIPO and/or at the WTO, risking consigning the whole enterprise to oblivion. An illustration of this issue can be found in the position of the European Union in this regard. While the EU initially supported the adoption of a binding disclosure requirement of the country of origin of genetic resources and associated traditional knowledge for all patent applications [79], this idea was completely left out of the European Commission's proposal on the implementation of the Nagoya Protocol. However, the case of Belgium offers some advantages in this regard, as the country has already introduced a limited disclosure requirement, described above. Amending it to make it compliant with the Nagoya Protocol could be a useful and cost-effective form of "game structuring" which would contribute to the minimization of the risk of misappropriation of genetic resources and traditional knowledge by Belgian users (at least for those utilizations leading to patenting). Furthermore, Hoare and Tarasofsky [78] consider that, while uncertainty remains, the disclosure requirement has potential to enhance sustainable development within the ABS regime and to foster trust between the stakeholders. Belgium, thus, should not wait for the completion of an endless discussion on the disclosure requirement.

The divergent conceptions of public action underlying this conflict overlap with our distinction between self-regulation and institutionalization of ABS. The Protocol's primary objective is to ensure that providers — situated at the beginning of the development chain — get a fair and equitable share of benefits (possibly including the sharing of intellectual property rights) with the objective of promoting 
the conservation and sustainable use of biodiversity. The TRIPS Agreement, however, defends the protection of exclusive rights for end-users: such protection is supposed to foster innovation and economic development, as it promotes the free contractual coordination of an actor's preferences [48]. In this framework, the exclusive rights granted by the Nagoya Protocol are in fact likely to "[result] in restricted access to these genetic resources, while such access is, subject to certain conditions, to be facilitated under the CBD" ([5], p. 89). West notes in this sense that despite this beyond-the-market view of the CBD and the Protocol's stated objective of benefit-sharing and facilitated access, the Nagoya Protocol too came to incorporate the market-centered view of intellectual property law as an economic right and necessary for innovation, thereby being "insufficient to ensure that [...] benefits are adequately distributed" ([48], p. 41).

The second impact of multi-level governance on implementation strategies is related to the process of denationalization. Indeed, the problems related to multi-level implementation in Belgium are further emphasized by a denationalization process through successive state reforms transferring competences to federated entities since 1970. The division of environmental, scientific and economic competences between the different Regions and Communities is fertile ground for regulatory competition between the federated entities and could potentially lead to a "race to the bottom of ABS" ([4], p. 64) without close cooperation between the federated entities.

Such regulatory competition is unlikely to have a major impact on Belgium as a provider of genetic resources, as no major instances are known of high-value downstream use by foreign users of Belgian endemic genetic resources. In a first stage, the Regions are more likely to adopt simple notification procedures for accessing genetic resources. Possible further decisions will be probably submitted on the evidence of a real flow of endemic genetic resources from Belgian territory.

In the case of the user-compliance and monitoring measures to be taken by Belgium, the situation is however different. As mentioned in the introduction, Belgium is a major user of genetic resources, counted among the most important biotechnology players in the EU and the world. More than half of Belgian biotechnology companies are located in Flanders, about a third are situated in Wallonia, and the rest in the Brussels-Capital Region. All three regions have set-up specific biotechnology initiatives, fund major biotechnology research in universities and compete to attract biotechnology companies to settle on their territory. Together with the high dispersion of ABS-competences over the Belgian territory, which might also impact measures for user-compliance, it might, thus, end up with four different ABS regimes on its territory, with some regions pushing towards very light user-compliance and monitoring measures in order to be more attractive for major private sector players and researchers. Avoiding this will require close cooperation and standardization between the Regions and the Federal government, delineating shared principles necessary for user compliance in Belgium, for example through the Belgian Coordination Committee on International Environmental Policy. However, with each power-level guarding its prerogatives, this is unlikely to be specific enough for a harmonization of social and environmental norms to take place in day-to-day implementation of the Protocol. This market-centered self-regulatory approach to user-compliance, which would leave the choice over monitoring measures to the self-regulation of these actors, is highly likely to lead to progressively downgraded monitoring. This is especially relevant in the context of the due diligence approach of the proposed EU regulation. 
Finally, the third impact of multi-level governance on the possibility to move towards a more institutional implementation approach is related to the process of destatization. The global reinforcement of the role private stakeholders play in the negotiation of material acquisition and transfer agreements is both the source and the consequence of destatization. The so-called erosion of the traditional forms of public action gives more room for informal governance networks [55,56]. In this context, the self-regulatory approach takes for granted that the actor's coordination contributes to the equalization of their resources, the conclusion of a fair transaction and Pareto-optimal economic equilibrium. However, in the context of the highly globalized exchange of genetic resources, this approach might lead to undervaluing the unbalanced bargaining capacity across the stakeholders, especially small commercial users and non-commercial users who do not have sufficient capacity to negotiate and/or compete with stronger players and might lack the administrative capacity to draft the required material transfer agreements in accordance with the Nagoya Protocol. Acknowledged through Article 22 [80] of the Nagoya Protocol, the issue of capacities seems to apply only to the reinforcement of capacities in developing countries. The measures proposed in the same article could-and should-However be used as well in developed user countries such as Belgium: as underscored in the Protocol itself, there is a need for each Party to "identify national capacity needs and priorities trough national capacity self-assessments" [80]. Previous research has shown that the Convention and its ABS provisions are still little known among certain group of stakeholders in Belgium, particularly private actors in downstream development (i.e., commercialization) [45].

Beyond the possible bargaining inequalities within the same national playing field, self-regulatory governance also had an impact on global justice. Unequal exchange capacities often occur between users from developed countries and providers from developing countries. Not only can this situation potentially lead to environmental degradation, abuses of the rights of indigenous people and local communities, and impact on the human development and the sustainability of traditional ways of living. It also conditions the fairness of the sharing of benefits to the capacity of both provider and user to negotiate. In this context, it can be argued that full user flexibility with regards to the exchange of genetic resources and the sharing of benefits will only exacerbate the bargaining unbalance issue.

Up to a certain extent, the wording of the Nagoya Protocol, in its benefit-sharing provisions, already provides for a possibility to address this unbalance. Indeed, paragraph 3 of Article 5 [80] indicates that the measures to implement the benefit-sharing obligation shall be taken not only by provider countries, but also by countries where the genetic resources and the traditional knowledge are being used [81]. A possible measure in this respect could be the promotion by the Federal government and the federated entities of standard agreements, thereby eliminating variations between ABS regimes and leveling the playing field for stakeholders [82]. Standardized contracts can also, and more importantly, facilitate the legal enforcement of contracts. Indeed, as Tvedt and Fauchald put it, "a contract would be binding as long as it is not found to be void, and could, depending on the dispute settlement clause included in the contract, be brought to arbitration" ([83], p. 392). With regards to benefit-sharing, standardizing the negotiation and/or the agreement allows overcoming unbalanced bargaining power resulting from asymmetries in information, knowledge, negotiation, skills, and capacity [82]. The standards established by the IPEN code of conduct and MOSAICC can clearly contribute to these goals and deserve to be supported and promoted by the user countries. Finally, as far as the detailed terms and conditions of these contracts are available to the state, standardized contract and procedures allow to 
monitor if benefits arising from potentially high-value resources are being shared accordingly to their value and according to the provider countries' legislation, and if the benefit sharing serves the objectives of the Protocol and the Convention.

\section{Conclusions}

We have argued in this paper that a simple facilitation of a market for genetic resources is doomed to fall short of achieving the objectives of the Nagoya Protocol. Transnational justice issues and inter- and intra-national conservation of the environment are unlikely to be adequately addressed through a market-based self-regulatory approach. For these objectives to be met, countries should move from the minimum focus on market-based meta-regulation of providers and users of genetic resources, towards more sustainable forms of regulation, which translate the normative goals both into legal principles and public policy. However, such a move appears particularly challenging in the context of multi-level governance that characterizes the implementation of the Protocol.

Through the analysis of the triple reality of the multi-level implementation of the Protocol-internationalization, denationalization, and destatization - this paper provides answers to the research questions in the introduction and identified, through an in depth analysis of the case of Belgium, three core challenges to moving away from a market-centered self-regulatory approach.

First, the internationalization and institutional interplay with the rules of the global economy might generate strong pressure to adopt a minimalist implementation approach close the self-regulatory implementation process outlined in this paper, thereby mainly facilitating self-regulated bilateral commercial exchange between stakeholders and relying on existing liability and redress opportunities offered by private, public, and criminal law. As illustrated through our case study of the options for implementation in Belgium, a combination of a set of light information sharing and monitoring measures and the application of existing general clauses of international private law, referring back to provider country legislation in case of litigation, could be considered sufficient in such a self-regulatory approach. Easier to set up, this approach might also be preferred to allow for timely ratification, making the country a Party to the Protocol and allowing it to join the negotiation table when the Protocol enters into force. The same challenges of global institutional interplay probably play a role also for other countries faced to multi-level governance constraints. Indeed, the approach taken by the European Commission in this respect, together with the influence of international trade-related processes at the WTO and WIPO on the implementation of ABS are likely to further reinforce this economic rationality, focusing on the minimization of users' burdens and costs and facilitating easy access to genetic resources. However, as argued above, national public policies, which would take steps to move towards further harmonization could contribute to avoiding such possible deadlocks. An example of such harmonization discussed in this paper is the introduction of a generalized information disclosure requirement for genetic resources, which already exists in Belgium.

Second, countries are increasingly confronted by powerful corporate interests (denationalization). As seen in the case study of the challenges faced in Belgium, highly decentralized ABS-competences between the Regions and the Federal government and the importance of biotechnology for their economies might fuel a race to the bottom in a context of internal competition, hoping to attract private sector investment in key economic sectors and spur the market in genetic resources. This is especially 
relevant for the cooperation on the obligations related to user-compliance, as it is unlikely that private actors will promote effective monitoring measures on their own without clear guarantees that all players have to make similar efforts.

Third, the global reinforcement of the role private stakeholders (i.e., the destatization) will exacerbate the unequal distribution of power and resources necessary to conclude fair and equitable agreements. Without capacity building and strong direct legal protection for small commercial and non-commercial entities in all countries and for providers in developing countries that are Parties to the Protocol, these players might not be in a position to comply with the administrative procedures and/or obtain fair and balanced exchange agreements in accordance with the Nagoya Protocol. Self-regulatory coordination through information sharing and lightweight monitoring measures will clearly fall short of building the necessary capacity of these key actors in the ABS regime. However, in Belgium, the state and stakeholders have developed or contributed to the development of transnational ABS agreements through MOSAICC and the IPEN code of conduct, thereby standardizing the exchange of genetic resources.

This paper has also identified additional potential solutions to overcome some of the drawbacks of a self-regulated approach through institutional public policy measures, which can be useful to guide the implementation in other countries faced with the specific pressures coming from the multi-level governance context. Examples include the establishment of standard agreements and procedures; capacity building initiatives in the context of international development cooperation; the inclusion of a meta-regulator as a fully-fledged stakeholder of ABS agreements; the creation of behavioral incentives such as quality labels; the inclusion and empowerment of civil society actors in the implementation of the Protocol; or the use of effective discloser requirements and the creation of an efficient monitoring system.

Finally, as indicated earlier, Belgium is an important political player in the access and benefit-sharing regime. A strong signal from the country could encourage countries faced with similar multi-governance challenges to step-up their efforts towards the implementation of the Nagoya Protocol. Like others [77], our analysis therefore suggests "that they should not wait for the Protocol becoming binding, and that they should take measures which follow reason and not establish the minimum which is absolutely commanded by the Protocol". International instruments, which are mutually supportive of (or even reinforce) the social and environmental objectives of the Nagoya Protocol and to which Belgium already is a Party (the ILO conventions, Agenda 21, the ITPGRFA and the CBD itself), provide a legal basis for a beyond-the-market approach for the implementation of ABS-related provisions. As argued in this paper, an institutional approach to implementation, which can include some of the legal and public policy measures for supporting collective action initiatives highlighted throughout this paper, could contribute to overcoming the triple implementation deadlock that can result from the internationalization, denationalization, and destatization trends analyzed in this paper.

\section{Acknowledgments}

We acknowledge co-funding from the European Commission, under the PF7 project GENCOMMONS (ERC grant agreement 284) and co-funding from the National Science Foundation (MIS Global Science Commons). We also gratefully acknowledge the discussions on the implementation of the Nagoya Protocol with the members of the Belgian Coordination Committee on International 
Environmental Policy, in particular Francis Brancart, Joanna Spanoudis, Leen Chanet, Delphine Perremans, Dries Van Eeckhoute, and Ines Verleye, who were a source of invaluable technical knowledge on the specific implementation context in Belgium.

\section{Conflicts of Interest}

The authors declare no conflict of interest.

\section{References and notes}

1. Convention on Biological Diversity; United Nations, 1992. Available online: http://www.cbd.int/doc/legal/cbd-en.pdf (accessed on 15 June 2013).

2. Mgbeoji, I. Beyond rhetoric: State sovereignty, common concern, and the inapplicability of the common heritage concept to plant genetic resources. Leiden J. Int. Law 2003, 16, 821-837.

3. Hufty, M. La gouvernance internationale de la biodiversité. Études Int. 2001, 32, 5-29, (in French).

4. Vogel, J.H. Reflecting Financial and Other Incentives of the TMOIFGR: The biodiversity Cartel. In A Moving Target: Genetic Resources and Options for Tracking and Monitoring Their International Flows; Muller, M.R., Lapeña, I., Eds.; International Union for Conservation of Nature (IUCN): Gland, Switzerland, 2007.

5. Rosendal, K.G. The Convention on Biological Diversity: Tensions with the WTO Trips Agreement over Access to Genetic Resources and the Sharing of Benefits. In Institutional Interaction in Global Environmental Governance: Synergy and Conflict among International and EU Policies; Oberthür, S., Gehring, T., Eds.; MIT Press: Cambridge, UK, 2006; pp. 79-102.

6. Aubertin, C.; Filoche, G. The Nagoya Protocol on the use of genetic resources: One embodiment of an endless discussion. Sustentabilidade Em Debate 2011, 2, 51-64.

7. Dedeurwaerdere, T.; Broggiato, A.; Manou, D. Global Scientific Research Commons under the Nagoya Protocol: Governing Pools of Microbial Genetic Resources. In Common Pools of Genetic Resources: Equity and Innovation in International Biodiversity Law; Kamau, E.C., Winter, G., Eds.; Taylor \& Francis: London, UK, 2013.

8. Chiarolla, C. Making Sense of the Draft Protocol on Access and Benefit Sharing for COP 10; Institute for Sustainable Development and International Relations (IDDRI): Paris, France, 2010; p. 11.

9. Aubertin, C.; Pinton, F.; Boisvert, V. Les Marchés de la Biodiversité (in French), IRD ed.; Institut de Recherche Pour le Développement: Paris, France, 2007.

10. Dedeurwaerdere, T. From bioprospecting to reflexive governance. Ecol. Econ. 2005, 53, 473-491.

11. Shepsle, K.A. Rational Choice Institutionalism. In The Oxford Handbook of Political Institutions; Rhodes, R.A.W., Binder, S.A., Rockman, B.A., Eds.; Oxford University Press: Oxford, UK, 2006.

12. Bolton, P.A.; Dewatripont, M.A. Contract Theory; MIT Press: Cambridge, UK, 2005.

13. Meyer, J.W.; Rowan, B. Institutional organizations: Formal structure as myth and ceremony. Am. J. Soc. 1977, 83, 340-363.

14. Scott, W.R. Institutions and Organizations; SAGE Publications: Thousand Oaks, CA, USA, 2001.

15. Auld, G.; Balboa, C.; Bernstein, S.; Cashore, B. The Emergence of Non-State Market-Driven (NSMD) Global Environmental Governance: A Cross-Sectoral Assessment. In Governance for the Environment; Delmas, M.A., Young, O.R., Eds.; Cambridge University Press: Cambridge, UK, 2009. 
16. Senden, L. Soft law, self-regulation and co-regulation in European law: Where do they meet? Electron. J. Comp. Law 2005, 9, 1-27.

17. Martin, A.; McGuire, S.; Sullivan, S. Global environmental justice and biodiversity conservation. Geogr. J. 2013, 179, 122-131.

18. De Jonge, B. What is fair and equitable benefit-sharing? J. Agric. Environ. Ethics 2011, 24, 127-146.

19. Hall, P.A.; Taylor, R.C.R. Political science and the three new institutionalisms. Polit. Stud. 1996, 44, 936-957.

20. Morgan, B. Social Citizenship in the Shadow of Competition: The Bureaucratic Politics of Regulatory Justification; Ashgate Publishing: Surrey, UK, 2003; p. 6.

21. Jessop, B. Capitalism and its future: Remarks on regulation, government and governance. Rev. Int. Polit. Econ. 1997, 4, 561-581.

22. Bries, F.; Albert, S. Belgian Biotechnology; Belgian Foreign Trade Agency: Brussels, Belgium, 2011. Available online: http://www.abh-ace.be/en/binaries/BIOTECH_WEB_tcm450-131446.pdf (accessed on 15 June 2013).

23. Figures from UN Comtrade, Medicinal and Pharmaceutical Products, other than Medicament (SITC 541) and Medicaments (including Veterinary Medicaments) (SITC 542). United Nations Commodity Trade Statistics Database: New York, NY, USA, 2011. Available online: http://comtrade.un.org/ (accessed on 15 June 2013).

24. Geeraerts, K.; Tilche, N.; Gerstetter, C.; Smith, E.; Shine, C.; Pallemaerts, M.; Antoine, M.; Brink, P. Study to Analyse Legal and Economic Aspects of Implementing the Nagoya Protocol on ABS in the European Union; Institute for European Environmental Policy: Brussels, Belgium, 2012.

25. Proposal for a Regulation of the European Parliament and of the Council on Access to Genetic Resources and the Fair and Equitable Sharing of Benefits Arising from their Utilization in the Union; COM(2012) 576 Final; European Commission: Brussels, Belgium, 10 April 2012.

26. Committee on Development of the European Parliament. Draft Opinion on the Proposal for a Regulation of the European Parliament and of the Council on Access to Genetic Resources and the Fair and Equitable Sharing of Benefits Arising from their Utilization in the Union; European Parliament: Brussels, Belgium, 19 March 2013. Available online: http:/www.europarl.europa.eu/ RegData/etudes/workshop/join/2013/507448/IPOL-ENVI_AT(2013)507448_EN.pdf (accessed on 15 June 2013).

27. Committee on the Environment, Public Health and Food Safety of the European Parliament. Draft Report on the Proposal for a Regulation of the European Parliament and of the Council on Access to Genetic Resources and the Fair and Equitable Sharing of Benefits Arising from their Utilization in the Union; European Parliament: Brussels, Belgium, 16 July 2013.

28. Gunningham, N. Environment law, regulation and governance: Shifting architectures. J. Environ. Law 2009, 21, 179-212.

29. O'Toole, L.J. Governing Outputs and Outcomes of Governance Networks. In Theories of Democratic Network Governance; Sørensen, E., Torfing, J., Eds.; Palgrave Macmillan: Basingstoke, UK, 2008; p. 169.

30. Powell, W. Neither Market nor Hierarchy: Network Forms of Organizing. In Research in Organizational Behaviour; Staw, B., Kramer, R.M., Eds.; Elsevier: Amsterdam, The Netherlands, 2002; pp. 295-326. 
31. Castells, M. The Rise of the Network Society: The Information Age: Economy, Society and Culture; John Wiley \& Sons: Hoboken, NJ, USA, 2000.

32. Stoker, G. Governance as theory: Five propositions. Int. Soc. Sci. J. 1998, 50, 17-28.

33. Newig, J.; Günther, D.; Pahl-Wostl, C. Synapses in the Network: Learning in governance networks in the context of environmental management. Ecol. Soc. 2010, 15, Article 24.

34. Sørensen, E.; Torfing, J. Theoretical Approaches to Metagovernance. In Theories of Democratic Network Governance; Sørensen, E., Torfing, J., Eds.; Palgrave Macmillan: Basingstoke, UK, 2008; p. 169.

35. Kooiman, J. Modern Governance: New Government-Society Interactions; SAGE Publications: Thousand Oaks, CA, USA, 1993; pp. 1-280.

36. Dixit, A.K.; Nalebuff, B.J. Thinking Strategically: The Competitive Edge in Business, Politics, and Everyday Life; W. W. Norton \& Company: New York, NY, USA, 1993.

37. Fischer, F. Reframing Public Policy: Discursive Politics and Deliberative Practices: Discursive Politics and Deliberative Practices; Oxford University Press: Oxford, UK, 2003.

38. Fischer, F.; Forester, J. The Argumentative Turn in Policy Analysis and Planning; Duke University Press: Durham, NC, USA, 1993.

39. Pitseys, J. Discipline et transparence: Aux sources de la Méthode Ouverte de Coordination (II). Rev. Interdiscip. Etud. Jurid. 2007, 58, 150-180, (in French).

40. The effectiveness of such a method, however, is subject to discussion and can be appreciated [37,38] or criticized [39].

41. Beroe Inc Web Page. Nagoya Protocol and Its Implications on Pharmaceutical Industry; Beroe Inc.: Cary, NC, USA, March 2011. Available online: http://www.beroeinc.com/insights/whitepapers/ nagoya-protocol-and-its-implication-pharmaceutical-industry (accessed on 15 June 2013).

42. Czarniawska, B. Narratives in Social Science Research; SAGE Publications: Thousand Oaks, CA, USA, 2004.

43. Czarniawska, B. Narrating the Organization: Dramas of Institutional Identity; University of Chicago Press: Chicago, IL, USA, 1997.

44. Pitseys, J.; Ruwet, C. La Mise en Récit Comme Source de Motivation et de Légitimation au Cœur des Nouvelles Techniques de Regulation (in French). Droit et Société. Available online: http://biogov.uclouvain.be/staff/pitseys/Pitseys_Ruwet_2012.pdf (accessed on 15 June 2013).

45. Frison, C.; Dedeurwaerdere, T. Infrastructures Publiques et Régulations sur l'Accès Aux Ressources Génétiques et le Partage des Avantages qui découlent de Leur Utilisation Pour L'innovation de la Recherche des Sciences de la vie. Accès, Conservation et Utilisation de la Diversité Biologique dans L'intérêt Général (in French); Université Catholique de Louvain: Louvain-la-Neuve, Belgium, 2006.

46. Young, T.R.; Bailet, F.N. Covering ABS: Addressing the Need for Sectoral, Geographical, Legal and International Integration in the ABS Regime; International Union for Conservation of Nature (IUCN): Gland, Switzerland, 2009.

47. Laird, S.; Wynberg, R. Bioscience at a Crossroads: Implementing the Nagoya Protocol on Access and Benefit-sharing in a Time of Scientific, Technological and Industry Change; Secretariat of the Convention on Biological Diversity: Montreal, Canada, 2012. 
48. West, S. Institutionalised exclusion: The political economy of benefit sharing and intellectual property. Law Environ. Dev. J. 2012, 8, 21-41.

49. Sonnenfeld, D.A.; Mol, A.P.J. Globalization and the transformation of environmental governance: An introduction. Am. Behav. Sci. 2002, 45, 1318-1339.

50. Richerzhagen, C. Effective governance of access and benefit-sharing under the Convention on Biological Diversity. Biodivers. Conserv. 2011, 20, 2243-2261.

51. Coolsaet, B.; Dedeurwaerdere, T.; Pitseys, J.; Batur, F. Study for the implementation in Belgium of the Nagoya Protocol on Access and Benefit Sharing to the Convention on Biological Diversity; Université Catholique de Louvain: Brussels, Belgium, 2013; p. 249.

52. Convention on Biological Diversity (CBD) Web Page. Report of the First Meeting of the Open-Ended Ad Hoc Intergovernmental Committee for the Nagoya Protocol on Access to Genetic Resources and the Fair and Equitable Sharing of Benefits Arising from their Utilization; $\mathrm{UNEP} / \mathrm{CBD} / \mathrm{ICNP} / 1 / 8$; Secretariat of the Convention on Biological Diversity: Montreal, Canada, 2011. Available online: http://www.cbd.int/absicnp1/documents/ (accessed on 15 June 2013).

53. Pierre, J. Debating Governance; Oxford University Press: Oxford, UK, 2000; p. 14.

54. Jessop, B. Multilevel governance and multilevel metagovernance. Changes in the EU as Integral Moments in the Transformation and Reorientation of Contemporary Statehood. In Multi-Level Governance; Bache, I., Flinders, M.V., Eds.; Oxford University Press: Oxford, UK, 2004.

55. Aman, A.C. Globalization, democracy, and the need for a new administrative law. Indiana J. Glob. Leg. Stud. 2003, 10, 125-155.

56. Rhodes, R.A.W. The hollowing out of the state: The changing nature of the public service in Britain. Polit. Quart. 1994, 65, 138-151.

57. Raustiala, K.; Victor, D.G. The regime complex for plant genetic resources. Int. Organ. 2004, 58, 277-309.

58. Oberthür, S.; Pożarowska, J. The Impact of the Nagoya Protocol on the Evolving Institutional Complex of ABS Governance. In Global Governance of Genetic Resources: Access and Benefit Sharing after the Nagoya Protocol; Oberthür, S., Rosendal, G.K., Eds.; Taylor \& Francis: London, UK, 2013.

59. Sand, H.P. Sovereignty bounded: Public trusteeship for common pool resources? Glob. Environ. Polit. 2004, 4, 47-71.

60. CBD ratification process in Belgium. Convention on Biological Diversity. The Federal government and the federated entities ratified the CBD on 22 November 1996 (Belgian Official Journal, 2 April 1997; pp. 7671-7692). Available online: http://www.biodiv.be/implementation/ ratification/ (accessed on 18 October 2013).

61. The International Treaty Web Page. International Treaty on Plant Genetic Resources for Food and Agriculture, Food and Agriculture Organization of the United Nations; The International Treaty: Rome, Italy. Available online: http://www.planttreaty.org/content/texts-treaty-official-versions (accessed on 15 June 2013). 
62. The text of the Treaty reads: "The objectives of this Treaty are the conservation and sustainable use of plant genetic resources for food and agriculture and the fair and equitable sharing of the benefits arising out of their use, in harmony with the Convention on Biological Diversity, for sustainable agriculture and food security." (Article 1.1) and "These objectives will be attained by closely linking this Treaty to the Food and Agriculture Organization of the United Nations and to the Convention on Biological Diversity." (Article 1.2).

63. Medaglia, J.C.; Tvedt, M.W.; Perron-Welch, F.; Jørem, A.; Phillips, F.K. The Interface between the Nagoya Protocol on ABS and the ITPGRFA at the International Level. Potential Issues for Consideration in Supporting Mutually Supportive Implementation at the National Level; Fridtjof Nansen Institute: Lysaker, Norway, 2013.

64. Riccardo, P. The Nagoya Protocol and WTO law. In The 2010 Nagoya Protocol on Access and Benefit-sharing in Perspective: Implications for International Law and Implementation Challenges; Morgera, E., Buck, M., Tsioumani, E., Eds.; Martinus Nijhoff Publishers: Leiden, The Netherlands, 2012; p. 185.

65. Vivas-Eugui, D. Bridging the Gap on Intellectual Property and Genetic Resources in WIPO's Intergovernmental Committee (IGC); International Centre for Trade and Sustainable Development (ICTSD): Geneva, Switzerland, 2012.

66. Intergovernmental Committee on Intellectual Property and Genetic Resources, Traditional Knowledge and Folklore; WIPO/GRTKF/IC/23/8; World Intellectual Property Organization: Geneva, Switzerland, 26 April 2013. Available online: http://www.wipo.int/edocs/mdocs/tk/en/ wipo_grtkf_ic_24/wipo_grtkf_ic_24_ref_grtkf_23_8_prov_2.pdf (accessed on 15 June 2013).

67. World Trade Organization Web Page. For the latest developments and documents concerning the review of Article 27.3(b) of the TRIPS Agreement. Available online: http://www.wto.org/english/ tratop_e/trips_e/art27_3b_e.htm (accessed on 15 June 2013).

68. Carr, J. Agreements that divide: TRIPS vs. CBD and proposals for mandatory disclosure of source and origin of genetic resources in patent applications. J. Transnatl. Law Policy 2008, 18, 131.

69. Decreet betreffende het Natuurbehoud en het Natuurlijk Milieu, 21 October 1997. (Belgian Official Journal, 10 January 1998). (Regional environmental decree). Available online: http://codex.vlaanderen.be/Zoeken/Document.aspx?DID=1005915\&AID=1024865\&param=inhoud (accessed on 15 June 2013).

70. Code Wallon de l'aménagement du Territoire, de L'urbanisme, du Patrimoine et de L'énergie (in French), 14 May 1984 (Belgian Official Journal, 19 May 1984). (Regional environmental code) Available online: http://wallex.wallonie.be/index.php?doc=1423 (accessed on 15 June 2013).

71. Ordonnance Relative à la Conservation de la Nature, 1er Mars 2012 (in French) (Belgian Official Journal, 16 March 2012). (Regional ordinance) Available online: http://www.ejustice.just. fgov.be/cgi_loi/change_lg.pl?language $=$ fr\&la $=$ F\&table_name $=$ loi\&cn=2012030115 (accessed on 15 June 2013).

72. Buck, M.; Hamilton, C. The Nagoya Protocol on access to genetic resources and the fair and equitable sharing of benefits arising from their utilization to the Convention on Biological Diversity. Rev. Eur. Community Int. Environ. Law 2011, 20, 47-61. 
73. Convention on Biological Diversity (CBD) Web Page. Nagoya Protocol on Access to Genetic Resources and the Fair and Equitable Sharing of Benefits Arising from Their Utilization to the Convention on Biological Diversity, Nagoya, 29 October 2010; Article 6.3(g). Available online: http://www.cbd.int/abs/text/articles/default.shtml?sec=abs-06 (accessed on 15 June 2013).

74. Belgian Co-ordinated Collections of Micro-Organisms (BCCM). Material Transfer Agreement, Terms and Conditions Applicable to the Use, Handling, Supply, Distribution, Sale, and Any Disposition of the Material; Belgian Co-ordinated Collections of Micro-Organisms: Brussels, Belgium, January 2007. Available online: http://bccm.belspo.be/services/bccm_mta.pdf (accessed on 15 June 2013).

75. Agreement on the Supply of Living Plant Material for Non-Commercial Purposes Leaving the International Plant Exchange Network; National Botanic Garden of Belgium: Meise, Belgium, 2012. Available online: http://www.br.fgov.be/RESEARCH/COLLECTIONS/LIVING/ INDEX_SEMINUM/BR_IS2012_MTA.pdf (accessed on 15 June 2013).

76. Withana, S.; Baldock, D.; Coolsaet, B.; Volkery, A. The Future of EU Environmental Policy: Challenges \& Opportunities; Institute for European Environmental Policy: Brussels, Belgium, 2012.

77. Kamau, E.C.; Fedder, B.; Winter, G. The Nagoya Protocol on access to genetic resources and benefit sharing: What is new and what are the implications for provider and user countries and the scientific community? Law Dev. J. 2010, 6, 248-263.

78. Hoare, A.L.; Tarasofsky, R.G. Asking and telling: Can "Disclosure of Origin" requirements in patent applications make a difference? J. World Intellect. Prop. 2007, 10, 149-169.

79. See the letter dated 11 May 2005 by the Permanent Delegation of the European Commission to the International Organizations in Geneva addressed to WIPO's Intergovernmental Committee on Intellectual Property and Genetic Resources, Traditional Knowledge and Folklore (WIPO/GRTKF/IC/8/11). World Intellectual Property Organization: Geneva, Switzerland, 2005. Available online: http://www.wipo.int/edocs/mdocs/tk/en/wipo_grtkf_ic_8/wipo_grtkf_ic_8_11.pdf (accessed on 15 June 2013).

80. Convention on Biological Diversity (CBD) Web Page. Nagoya Protocol on Access to Genetic Resources and the Fair and Equitable Sharing of Benefits Arising from Their Utilization to the Convention on Biological Diversity; Secretariat of the Convention on Biological Diversity: Montreal, Canada; Available online: http://www.cbd.int/abs/text/default.shtml (accessed on 15 June 2013).

81. Greiber, T.; Moreno, S.P.; Åhrén, M.; Carrasco, J.N.; Kamau, E.C.; Medaglia, J.C.; Oliva, M.J.; Perron-Welch, F. An Explanatory Guide to the Nagoya Protocol on Access and Benefit-Sharing; IUCN: Gland, Switzerland, 2012; p. 372.

82. Täuber, S.; Holm-Müller, K.; Jacob, T.; Feit, U. An Economic Analysis of New Instruments for Access and Benefit-Sharing under the CBD-Standardisation Options for ABS Transactions; Bundesamt für Naturschutz: Bonn, Germany, 2011.

83. Tvedt, M.W.; Fauchald, O.K. Implementing the Nagoya Protocol on ABS: A hypothetical case study on enforcing benefit sharing in Norway. J. World Intellect. Prop. 2011, 14, 383-402.

(C) 2013 by the authors; licensee MDPI, Basel, Switzerland. This article is an open access article distributed under the terms and conditions of the Creative Commons Attribution license (http://creativecommons.org/licenses/by/3.0/). 